new market. These doubts were reffected in the news that the World Health Organization is also sponsoring research on new rodenticides and they gave added force to the view that continuing support in the public sector is necessary for progress in this small but active and disproportionately important field of research.

\section{RESERVOIRS \\ More Midges, More Fish?}

INCREASING by artificial means the number of midge larvae in a reservoir seems a topsy turvy way of providing drinking water free of foreign bodies. Investigations by the Inland Fisheries Branch of the State of California Department of Fish and Game suggest, however, that midges and drinking water are not so incompatible as they might seem (Fish Bull. Calif., No. 148; 1970). Midge larvae are important in the food chains of certain fish. Increasing the numbers of these larvae should therefore, in theory, provide more food for fish, and ultimately better fishing. If this can be done by a method of artificial destratification of the water, a practice incidentally which also improves the quality of water, the water authorities should be in business. It was an experiment which the California Department of Fish and Game thought worthwhile.

Midge larvae, together with tubificid worms, nematode worms and certain species of mollusc, are typical bottom dwelling animals of all freshwater lakes and reservoirs. But in summer months their distribution is limited and they may be absent from the deeper parts because the water there can become deoxygenated and the bottom muds are often toxic. This state of affairs is found particularly in lakes and reservoirs which are rich in nutrients (what limnologists call productive or eutrophic bodies of freshwater) and arises from a combination of physical factors.

In summer months when there is comparatively little wind to stir up the water, the upper layers warm up more quickly than the lower regions and a sharp division in temperature-a thermocline-is formed. Decomposition of organic matter in the deepest parts uses up the oxygen, and toxic materials accumulate in the mud at the -bottom. At certain depths therefore the reservoir or lake becomes divided into a lower, anaerobic cool layer or hypolimnion and an upper, warm aerobic epilimnion. In a particularly productive reservoir in which a large part of the water is deoxygenated, the water is obviously not very suitable for drinking and abstractions can then be made only from the epilimnion. One solution is to destratify such reservoirs artificially by injecting compressed air and the California Department of Fish and Game has already shown this to be feasible; it improves the quality of water by making the temperature and oxygen concentrations relatively uniform throughout the year. But how does destratification affect the bottom organisms such as midge larvae, which in a sharply stratified reservoir are presumably excluded from the toxic deep parts and therefore less available as food for fish? The department decided to investigate this problem in El Capitan Reservoir in San Diego County. The reservoir was destratified in 1965 and was not allowed to stratify again until 1967 . The bottom organisms were sampled by dredging in 1964 before destratification and in 1965 , 1966 and 1967.

During destratification midge larvae, oligochaete worms, nematode worms and clams rapidly invaded the deepest regions in summer and their total numbers increased dramatically. In stratified conditions in 1964, for example, midge larvae were practically absent below a depth of $10 \mathrm{~m}$ by July; in 1966 there were substantial numbers at $25 \mathrm{~m}$ or more. The oligochaetes and the nematode worms fluctuated in a similar manner.
It seems likely that a combination of factors-ample oxygen and food and warmer temperatures-led to the changes in the populations of bottom organisms, rather than oxygen alone. The El Capitan results certainly indicate that artificial destratification might retard or reverse natural eutrophication in such waters and make them less productive. This could, in theory, have a limiting effect on fish populations. On the other hand, changes in the distribution of food, such as midge larvae, and the better environmental conditions for fish in the hypolimnion in summer might more than counterbalance a minor decrease in productivity. This is a long term implication. Meanwhile, the California Department of Fish and Game is considering using artificial destratification in reservoirs like El Capitan as an alternative to heavy treatment with copper sulphate which is often used to remove algae and to make the water drinkable. This substance, it says, can have much more immediate effects on fish populations far worse than anything to be expected from destratification.

\title{
Another Biological Control Mechanism
}

Most molecular biologists would agree that a given structural gene dictates the amino-acid sequence of a protein and that, given this sequence, the polypeptide chain will fold itself into the "native" structure. In the case of proteins comprising more than one polypeptide chain there is, of course, the extra stage of subunit assembly. In next Wednesday's Nature New Biology, M. Rosenberg presents some findings which indicate that subunit assembly can be tissue specific inasmuch that different distributions of lactate dehydrogenase (LDH) isoenzymes are observed in different tissues although the component subunits are the same. The LDH molecule is known to be tetrameric and isoenzymes arise from the fact that different subunits, $A$ and $B$, assemble to give molecules of the structure $A_{4}$, $A_{3} B, A_{2} B_{2}, A_{3}$ and $B_{4}$. If the assembly of equal numbers of $A$ and $B$ chains is random, then these forms will occur in the binomial proportions of $1: 4: 6: 4: 1$.

In mammalian tissues there are usually five distinct isoenzymes although the distribution varies from tissue to tissue for a given animal. Rosenberg claims that this differential tissue distribution in mammals is explained simply by there being excess of one subunit over the other as a result of differential rates of synthesis of the two types of chain. In a number of fish, however, Rosenberg has found that there are only one, two or three isoenzymes and in fish with five isoenzymes the distribution is nonrandom. She was able to take a three isoenzyme mixture from the common mackerel (Scomber scombrus) and dissociate and reassociate it in vitro to give all five isoenzymes. Their relative migrations in an electric field indicated that the three isoenzymes in the original mixture were $\mathbf{A}_{4}, \mathbf{A}_{2} \mathbf{B}_{2}$ and $\mathbf{B}_{4}$ and this was confirmed by immunochemistry. Rosenberg showed in similar fashion that two isoenzyme fish $\mathrm{LDH}$ was $\mathrm{A}_{4}$ and $\mathbf{B}_{4}$ and one isoenzyme LDH was $\mathrm{A}_{2} \mathrm{~B}_{2}$.

The differential distribution of isoenzymes in different tissues of the same organism was well illustrated by the alewife (Alosa pseudoharengus) which had two, three and five isoenzymes in different tissues. Controls indicated that failure to observe the missing structures was not related to the fact that they were preferentially degraded in the extraction procedures.

Rosenberg concludes that the missing isoenzymes are absent because their dissociation rates are disproportionately high and that this could be a function of the different concentrations of ions, proteins and coenzymes in different tissues. Rosenberg's findings complement the statement by Jaenicke (in Pyridine Nucleotide Dependent Dehydrogenases, edit. by H.Sund, p. 70; SpringerVerlag, Berlin and New York; 1970) that the primary structure in conjunction with the specific solvent conditions is the major determinant of the threedimensional structure up to the level of quaternary structure. The mode of subunit assembly is thus potentially a further source of control in biological systems. 